\title{
Ambient noise Love wave tomography at a gold mine tailings storage facility
}

\author{
G. OLIVIER*, T. DE WIT†, F. BRENGUIER $\pitchfork$, L. BEZUIDENHOUT§ and T. KUNJWA
}

\begin{abstract}
Tailings storage facilities (TSFs) are some of the most challenging structures to operate in the mining industry. Some of these structures are susceptible to liquefaction and piping failure, and need to be monitored carefully. In this study, ambient seismic noise interferometry is applied to image the internal structure of a tailings storage facility (TSF) that showed signs of increased seepage. Twenty geophones were deployed along a roughly $100 \mathrm{~m}$ section of the TSF and recorded continuous seismic data. The ambient noise was used to create Love wave dispersion curves between sensor pairs, which were in turn inverted to estimate the shear wave velocity of the dam wall as a function of depth. The velocity profile indicated the phreatic surface roughly $10 \mathrm{~m}$ below the surface, with regions near the centre of the array showing the phreatic surface as close as $3 \mathrm{~m}$ below the surface. These areas are spatially well correlated with the area where increased seepage was identified and the results were comparable with cone penetration tests that were performed in the area. The study showed that the analysis of ambient seismic noise can be a cost-effective, fast and non-invasive method to image the internal structure of TSFs.
\end{abstract}

KEYWORDS: Geophysics; Mining \& quarrying; Monitoring

ICE Publishing: all rights reserved

\section{INTRODUCTION}

Tailings storage facilities (TSFs) are massive structures that contain the slurry and waste produced by the mining industry when processing raw ore. These structures are similar to earthen dams, but the height of these structures is regularly increased to accommodate more tailings over time. These increases in the dam wall (or lifts) can be made downstream or upstream.

Saturation and the location of the phreatic surface are important parameters for monitoring tailings dam walls. Increased saturation results in a reduced factor of safety and potentially higher liquefaction potential. To establish the location of the phreatic surface, Casagrande and vibrating wire piezometers are frequently used. Cone penetration tests $(\mathrm{CPTu})$ are also commonly used. These instruments give one-dimensional (1D) point measurements and interpolation between points is needed to establish a twodimensional (2D) model of the phreatic surface.

Geophysical methods such as electrical resistivity tomography (ERT), CPTu with pore water measurements and vibrating wire piezometers are well-established methods used to infer the location of the phreatic surface and to probe the state of the tailings. CPTu, Casagrande/vibrating wire piezometers and drill samples only provide point measurements and as a result many samples are needed to probe the entire area of interest. Basic interpolation methods are

Manuscript received 23 January 2018; first decision 17 June 2018; accepted 18 June 2018.

Published online at www.geotechniqueletters.com on 25 July 2018.

*Institute of Mine Seismology, Hobart, TAS, Australia (Orcid:0000-0002-2083-5895).

†Institute of Mine Seismology, Hobart, TAS, Australia.

Institut des Sciences de la Terre, Université Grenoble Alpes, Grenoble Cedex 9, France.

§AEON, Faculty of Science, Nelson Mandela Metropolitan University, Port Elizabeth, South Africa. commonly used to create a model of the phreatic surface based on point measurements, but due to the lack of spatial resolution these models cannot always capture small-scale local effects such as piping failure.

Seismic surveys and ERT are among the few methods that can image earthen structures continuously in space (as opposed to point measurements). As a result, these methods have proven to be quite effective to image earthen dams (Cho \& Yeom, 2007; Osazuwa \& Chinedu, 2008; Sjödahl et al., 2008; Lin et al., 2013b; Ivanov et al., 2017). However, the results of these methods can be hard to interpret alone since hydrophysical and geological conditions (compaction, saturation, pore pressure, material type and so on) both impact subsurface velocity and resistivity. As a result, independent geophysical methods are often required to verify the findings of these surveys (Lin et al., 2013b).

Seismic surveys generally require an active source and an array of receivers. The depth penetration and range of seismic surveys are limited to the amount of power the active source is able to produce, while still remaining non-destructive. Passive seismic methods have evolved rapidly in recent years, and ambient seismic noise crosscorrelation is now a very popular method for seismologists to image the subsurface (Shapiro et al., 2005; Brenguier et al., 2007; Bensen et al., 2008; Lin et al., 2013a; Olivier et al., 2015). The method records background vibrations and uses seismic interferometry (normally by cross-correlation) to turn each sensor into a virtual active source. For surface wave analysis, this effectively means that an active source is no longer needed to image the subsurface. Ambient seismic noise interferometry has been applied to image and monitor earthen dams (Planès et al., 2015, 2017), but to our knowledge the method has not been used to image TSFs. In a recent example, ambient seismic noise interferometry was used to monitor the time-dependent seepage in a downstream tailings dam (Olivier et al., 2017).

Typically, Raleigh waves are used for surface wave analysis (Park et al., 1999), and only in recent years Love waves have been considered more frequently (Ivanov et al., 2017). 
When applying surface wave tomography in earthen dams, one of the most important features to be delineated is the soil saturation and the location of the phreatic surface. Raleigh waves are generated by the interference of the interactions of $\mathrm{P}$ - and $\mathrm{S}_{\mathrm{V}}$ waves with a free surface. In sandy soil, $\mathrm{P}$ - and $\mathrm{S}$-wave velocities have opposite responses to saturation, with $\mathrm{P}$-wave velocities increasing and $\mathrm{S}$-wave velocities decreasing with saturation (Carcione \& Helle, 2002). Unfortunately, this means that Raleigh waves can give ambiguous results when inverting dispersion curves to determine $\mathrm{S}$-wave velocity profiles in areas where saturation is an important consideration. Love waves on the other hand, are generated by only the interaction of $S_{H}$ waves with a free surface. Therefore, Love wave velocities respond uniquely and will decrease with saturation, all other factors being equal.

In this experiment, an array of geophones continuously recorded ambient seismic noise for 2 days. The purpose of the study was to determine whether ambient seismic noise could be used to image the internal structure of the dam wall. Virtual seismic source signals were constructed with seismic interferometry and used in analysis similar to the well-established multi-channel analysis of surface waves (MASW) method to create a high-resolution $2 \mathrm{D}$ shear wave velocity profile over a $95 \mathrm{~m}$ section of the dam wall. In the study it is postulated that Love waves are more applicable for investigating TSFs than Raleigh waves, due to the competing effects of saturation in sandy soil on Raleigh wave propagation velocity. The resulting velocity profile clearly indicates the phreatic surface as a zone of low velocity and an area where the low-velocity zone extends closer to the surface. This area is spatially well correlated with the area where the seepage manifested on the dam wall, indicating that the method is capable of imaging the internal structure of tailings dam walls. These findings were compared with a CPTu survey that was also conducted in the area and showed that the results are feasible.

\section{DATA AND METHODS}

For this study, a gold tailings storage facility (TSF) in Welkom, South Africa was considered that has experienced considerable seepage and erosion in certain parts of the dam. These parts of the dam consist of material with physical and mechanical properties similar to loose sand, dense sand or very soft clay in the top few meters and soft clay and/or soft clayey silt for the remainder of the wall up to the natural ground level as indicated by the equivalent soil behaviour-type profiles from CPTu testing (Van Wyk et al., 2017). Continuous seismic data were recorded by 20 three-component $14 \mathrm{~Hz}$ geophones for 2 days. The geophones were placed in a line along the dam wall with $5 \mathrm{~m}$ inter-sensor spacing. Data were sampled at 400 samples/s. The $95 \mathrm{~m}$ section where the geophones were deployed only accounts for a small section of the total embankment at one elevation. An aerial view of the entire dam and the section showing the seepage and vegetation growth on the dam wall is shown in Fig. 1 along with the locations of the geophones and CPTu probes.

To create Love wave virtual active source signals, the standard processing steps were used for ambient seismic noise surface wave tomography (Bensen et al., 2007). Continuous data are split into 10 min segments. The data segments are spectrally whitened between 5 and $50 \mathrm{~Hz}$. Data segments are cross-correlated between all $\left(\begin{array}{c}N \\ 2\end{array}\right)=190$ unique sensor pairs. The $10 \mathrm{~min}$ correlation functions are stacked for each pair of sensors. The vertical component correlation functions represent estimates of the Raleigh waves propagating between sensors, while the horizontal transverse correlation functions represent Love waves. As discussed earlier, the study of Love waves is believed to be more appropriate in this setting. The stacked Love wave seismograms are shown in Fig. 2 as a function of inter-station spacing. Each horizontal line represents the stacked correlation functions for station pairs with the same inter-station distance. These Love wave correlation functions show clear arrival fronts for positive and negative lag times. The arrival fronts correspond to the propagation velocity of the surface waves. The propagation velocities are low, but reasonable for sandy soil.

To create dispersion curves, a simple phase delay and stack method is employed (Park et al., 1999). In order to create a spatial map of shear wave velocity, consecutive sensors are grouped and the average dispersion curve for the group is calculated by phase delaying and stacking the correlation functions for each trial velocity at a given frequency. The high quality of the correlation functions and dispersion curves meant that the dispersion curves could be picked automatically with relative ease. The picked dispersion curves are assigned to the centroid of each group of sensors, so that a representative dispersion curve every $2.5 \mathrm{~m}$ is generated. An example of a Love wave dispersion curve is shown in Fig. 3.

\section{RESULTS}

To estimate the shear-wave velocity as a function of depth, an improved neighbourhood algorithm is used (Wathelet, 2008) to invert the dispersion curves. The result of one of these

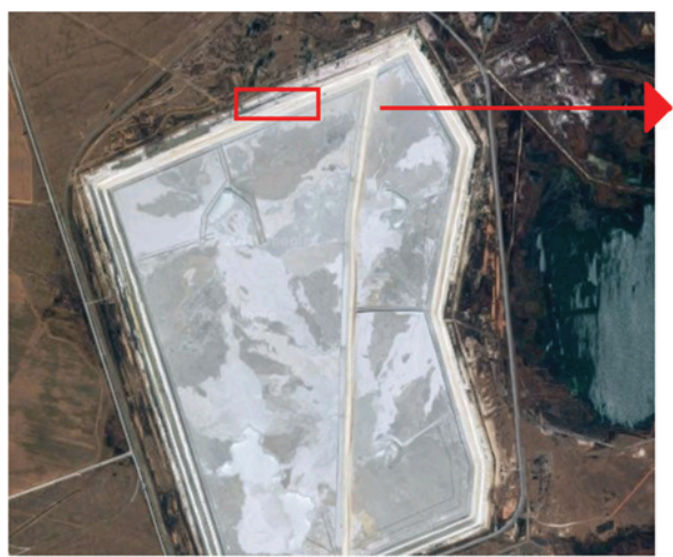

(a)

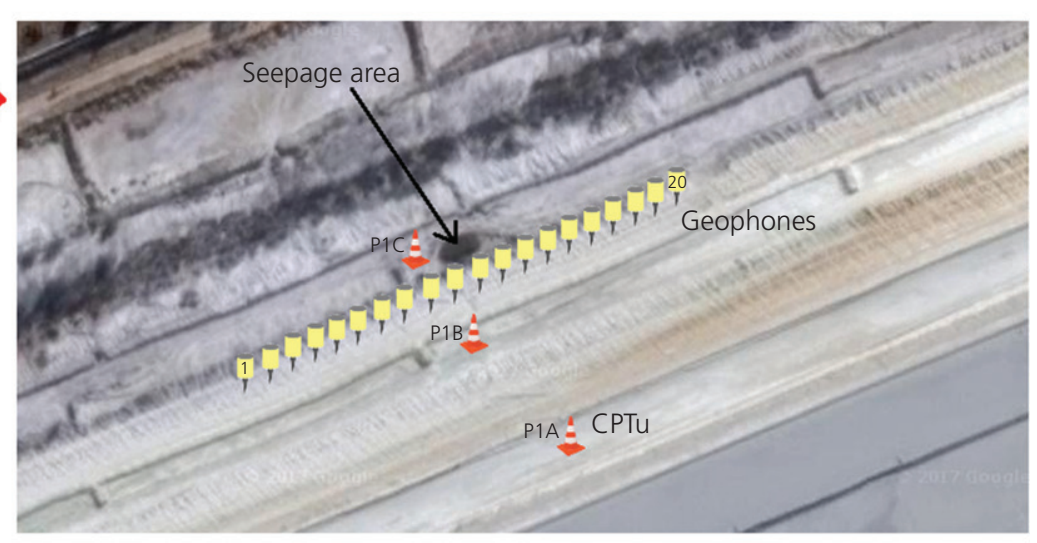

(b)

Fig. 1. Aerial view of the tailings dam with the area where the survey was conducted indicated in red (left). The locations of the geophones and CPTu tests are indicated, along with the area where excessive seepage was noticed 


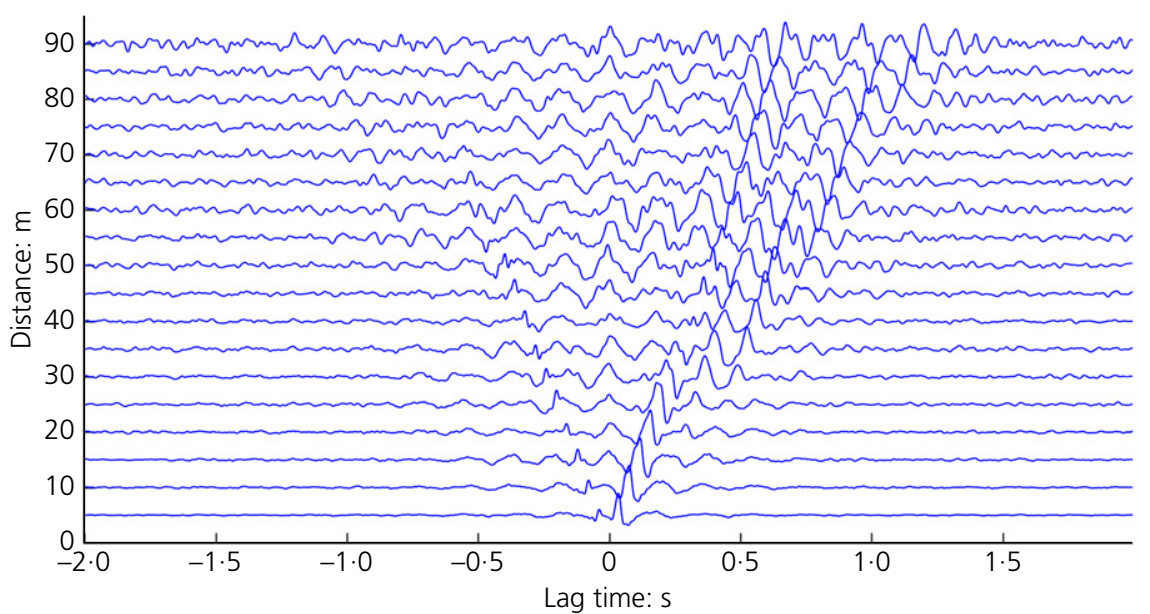

Fig. 2. The Love wave virtual source signals shown as a function of interstation distance. Clear arrival fronts are visible at positive and negative lag times

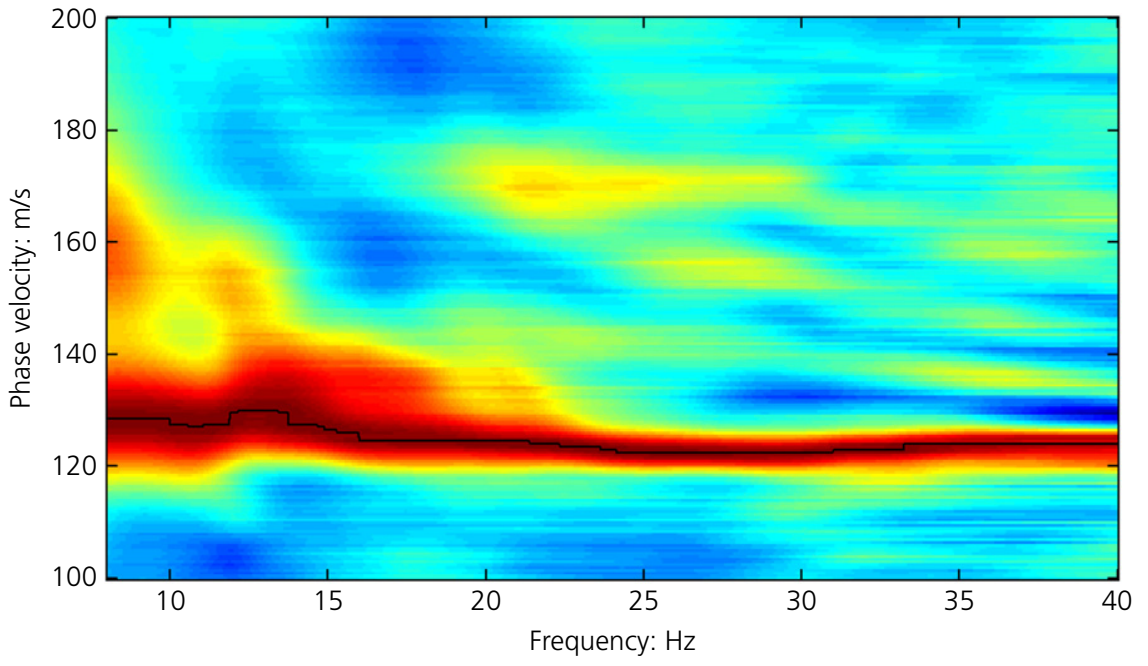

Fig. 3. Love wave dispersion curve, with the fundamental mode picks in black
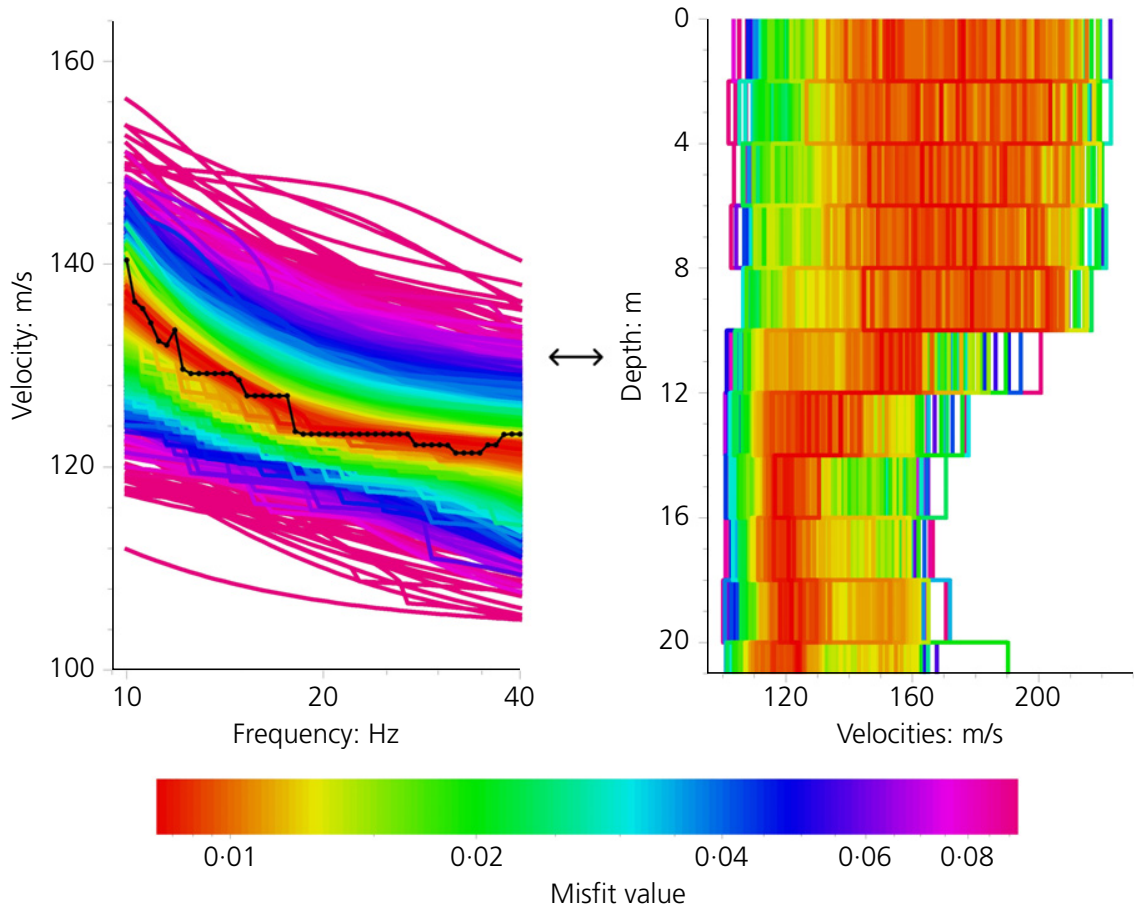

Fig. 4. Love wave dispersion curve inverted with a neighbourhood algorithm to find ground profile. The values in red indicate low misfit 


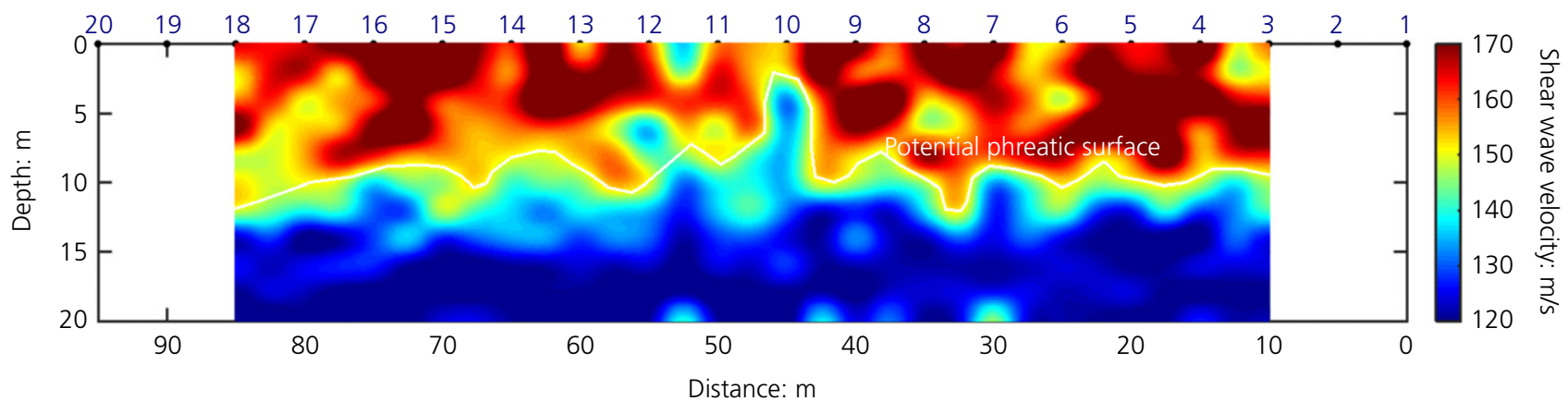

Fig. 5. 2D shear wave velocity profile over the $95 \mathrm{~m}$ section. The low-velocity zone below the white line likely corresponds to the phreatic surface. Near the middle of the array low-velocity fingers likely indicate seepage or internal erosion. The numbers at the top of the figure indicate the geophone positions

inversions is shown in Fig. 4 for a medium with ten $2 \mathrm{~m}$ layers. Interestingly, the S-wave ground profile here shows higher preferential velocities in the shallow section $(0-9 \mathrm{~m})$, with a clear drop in velocity around $10 \mathrm{~m}$. After all the 28 dispersion curves are inverted, the corresponding S-wave velocity profiles are allocated to the centroid of the sensor group used to create the dispersion curves. The profiles are interpolated to create a $2 \mathrm{D}$ shear wave velocity as a function of depth. The final result is shown in Fig. 5.

The lateral variations of the $\mathrm{S}$-wave velocity near-surface likely indicate the level of soil compaction (high velocity being dense sand, low velocity being loose sand or soft clay), with areas of low velocity also indicating increased liquefaction potential (Andrus \& Stokoe, 2000). Note there is a near-surface low-velocity zone at around $48 \mathrm{~m}$ along the profile, probably indicating very loose sand or very soft clay in this region. The $\mathrm{S}$-wave profile also shows a clear zone of low velocity around $10 \mathrm{~m}$ below the surface. Near the centre of the array (between 40 and $60 \mathrm{~m}$ ), there are two plumes with lower velocity indicating that the phreatic surface is closer to the surface. These areas are spatially well correlated with the areas on the surface of the dam wall that showed increased vegetation growth and seepage.

\section{Comparison with CPTu}

CPTu were conducted by Jones \& Wagener Consultants (Van Wyk et al., 2017) at three locations in a transverse
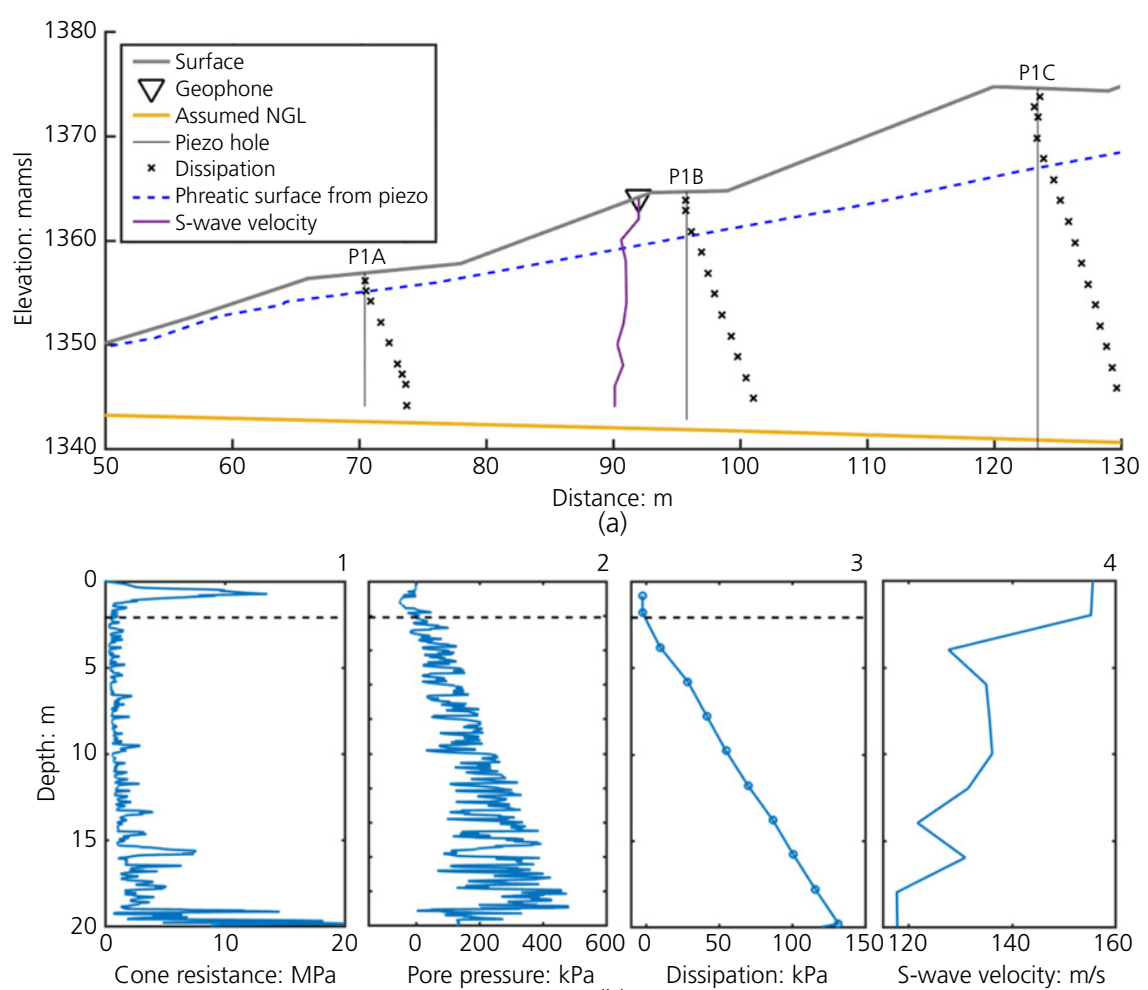

(b)

Fig. 6. Results from CPTu testing courtesy of Jones \& Wagener Consultants: (a) Schematic showing the dissipation measured in each CPTu test along with the interpreted phreatic surface. The S-wave velocity as a function of depth is also indicated below the geophone in the vicinity of the 2D line from the CPTu test. The interpolated phreatic surface from the CPTu indicate the phreatic surface is around $5 \mathrm{~m}$ below the surface and below the geophone, which is a good agreement with the seismic survey: (b) CPTu test results for P1B in panels 1-3. P1B is the closest probe to the geophone array and therefore the easiest to compare directly to the seismic survey. The $\mathrm{S}$-wave velocity from the seismic survey is indicated in panel 4 . The S-wave profile indicates the phreatic surface around $4 \mathrm{~m}$ below surface in this location. mamsl, metres above mean sea level 
direction at the centre of the geophone array (see Fig. 1 right). The main results of the CPTu testing and interpretation of the phreatic surface are shown in Fig. 6.

An example of the water pressures with depth as recorded by the piezocone probe during dissipation tests is given in Fig. 6(b) for hole P1B. The dynamic water pressure is shown in the second panel and the ambient pressure after dissipation in the third panel. A line fitted to the ambient pressure after dissipation and extrapolated back to zero pressure will indicate the likely position of the phreatic surface at the probe position. In this example, the phreatic surface is around $2 \cdot 1 \mathrm{~m}$ below the probe (indicated by the dashed line). The fourth panel shows the S-wave velocity as a function of depth. The S-wave velocity decreases between 2 and $4 \mathrm{~m}$ below surface, with the phreatic surface most likely being around $4 \mathrm{~m}$. This observation is consistent with the CPTu tests, considering the location of the geophone line with respect to the CPTu probes (see Fig. 6(a)). Even though the resolution of the two methods differ greatly and are hard to compare directly, the apparent agreement between the results inspire confidence in the findings of the seismic survey.

\section{DISCUSSION AND CONCLUSIONS}

TSFs are constantly growing structures that require diligent monitoring. Since these facilities may be susceptible to static liquefaction and internal erosion, internal signs of degradation, seepage or fluid saturation need to be known. Seismic methods are one of the few methods that can image the internal structure of these facilities continuously in space, as opposed to most geophysical methods that only provide point measurements. However, seismic methods have scarcely been used in this environment. In this study, the use of ambient seismic noise to image the internal structure of a short section of a TSF that has showed signs of increased seepage (visible water on surface and increased vegetation growth) is investigated. Estimates of the Love wave virtual source signals between sensors were constructed by crosscorrelating the seismic noise recorded in the horizontal transverse components of the geophones. These virtual source signals were used to create dispersion curves between different subsets of sensors. The dispersion curves were inverted with an improved neighbourhood algorithm to estimate the shear wave velocities as a function of depth across the $95 \mathrm{~m}$ section of the dam wall. The shear wave profile showed a low-velocity zone around $10 \mathrm{~m}$ below surface. Near the centre of the array, plumes of low-velocity zones were found between 3 and $8 \mathrm{~m}$ below the surface indicating that the phreatic surface is much closer to surface in this area. This area was spatially well correlated to where seepage was identified on the surface of the dam wall. The results of the study were compared with the CPTu carried out near the centre of the geophone array and the results were comparable.

The results of the trial indicated that ambient seismic noise Love wave tomography can be a cost-effective, fast and non-invasive method to image the internal structure of TSFs.

\section{REFERENCES}

Andrus, R. D. \& Stokoe, K. H. II (2000). Liquefaction resistance of soils from shear-wave velocity. J. Geotech. Geoenviron. Engng 126, No. 11, 1015-1025.

Bensen, G., Ritzwoller, M., Barmin, M., Levshin, A., Lin, F., Moschetti, M., Shapiro, N. \& Yang, Y. (2007). Processing seismic ambient noise data to obtain reliable broad-band surface wave dispersion measurements. Geophys. J. Int. 169, No. 3, 1239-1260.

Bensen, G. D., Ritzwoller, M. H. \& Shapiro, N. M. (2008). Broadband ambient noise surface wave tomography across the United States. J. Geophys. Res. 113, No. B5, 1239-1260.

Brenguier, F., Shapiro, N. M., Campillo, M., Nercessian, A. \& Ferrazzini, V. (2007). 3-D surface wave tomography of the Piton de la Fournaise volcano using seismic noise correlations. Geophys. Res. Lett. 34, No. 2, https://doi.org/10.1029/ 2006GL028586.

Carcione, J. M. \& Helle, H. B. (2002). Rock physics of geopressure and prediction of abnormal pore fluid pressures using seismic data. CSEG Recorder 27, No. 7, 8-32.

Cho, I. K. \& Yeom, J. Y. (2007). Crossline resistivity tomography for the delineation of anomalous seepage pathways in an embankment dam. Geophysics 72, No. 2, G31-G38.

Ivanov, J., Miller, R. D., Feigenbaum, D., Morton, S. L., Peterie, S. L. \& Dunbar, J. B. (2017). Revisiting levees in southern Texas using Love-wave multichannel analysis of surface waves with the high-resolution linear radon transform. Interpretation 5, No. 3, T287-T298.

Lin, F., Li, D., Clayton, R. W. \& Hollis, D. (2013a). High-resolution 3D shallow crustal structure in Long Beach, California: application of ambient noise tomography on a dense seismic array. Geophysics $\mathbf{7 8}$, No. 4, 45-56.

Lin, F. C., Tsai, V. C., Schmandt, B., Duputel, Z. \& Zhan, Z. (2013b). Extracting seismic core phases with array interferometry. Geophys. Res. Lett. 40, No. 6, 1049-1053.

Olivier, G., Brenguier, F., Campillo, M., Lynch, R. \& Roux, P. (2015). Body-wave reconstruction from ambient seismic noise correlations in an underground mine. Geophysics 80, No. 3, KS11-KS25.

Olivier, G., Brenguier, F., de Wit, T. \& Lynch, R. (2017) Monitoring the stability of tailings dam walls with ambient seismic noise. The Leading Edge 36, No. 4, 350a1-350a6.

Osazuwa, I. \& Chinedu, A. (2008). Seismic refraction tomography imaging of high-permeability zones beneath an earthen dam, in Zaria area, Nigeria. J. Appl. Geophys. 66, No. 1-2, 44-58.

Park, C. B., Miller, R. D. \& Xia, J. (1999). Multichannel analysis of surface waves. Geophysics 64, No. 3, 800-808.

Planès, T., Larose, E., Rossetto, V. \& Margerin, L. (2015). Imaging multiple local changes in heterogeneous media with diffuse waves. JASA 137, No. 2, 660-667.

Planès, T., Rittgers, J. B., Mooney, M. A., Kanning, W. \& Draganov, D. (2017). Monitoring the tidal response of a sea levee with ambient seismic noise. J. Appl. Geophys. 138, 255-263.

Shapiro, N., Campillo, M., Stehly, L. \& Ritzwoller, M. (2005). High resolution surface-wave tomography from ambient seismic noise. Science 307, No. 5715, 615-618.

Sjödahl, P., Dahlin, T., Johansson, S. \& Loke, M. (2008). Resistivity monitoring for leakage and internal erosion detection at Hällby embankment dam. J. Appl. Geophys. 65, No. 3-4, 155-164.

Van Wyk, M., Hörtkorn, F. \& Rust, M. (2017). FSS 8 west buttress CPTu report, Technical Report. Jones and Wagener, Johannesburg, South Africa.

Wathelet, M. (2008). An improved neighborhood algorithm: parameter conditions and dynamic scaling. Geophys. Res. Lett. 35, No. 9, https://doi.org/10.1029/2008GL033256.

\section{ACKNOWLEDGEMENTS}

The authors thank Jones \& Wagener Consultants and, in particular, Florian Hörtkorn who shared information about the site and gave comments that improved the report. The authors also acknowledge AEON at the Nelson Mandela University for providing data-acquisition units and funding for the instrument deployment.

\section{HOW CAN YOU CONTRIBUTE?}

To discuss this paper, please submit up to 500 words to the editor at journals@ice.org.uk. Your contribution will be forwarded to the author(s) for a reply and, if considered appropriate by the editorial board, it will be published as a discussion in a future issue of the journal. 